\title{
Alpha 2-antiplasmin deficiency in a Sudanese child: a case report
}

\author{
Bashir Abdrhman Bashir Mohammed ${ }^{*}$ (])
}

\begin{abstract}
Background: The plasma serine protease inhibitor alpha 2-antiplasmin $\left(a_{2}-A P\right.$, otherwise known as $a_{2}$-plasmin inhibitor) is a rapid-acting plasmin inhibitor recently found in human plasma, which seems to have a significant role in the regulation of in vivo fibrinolysis. Congenital deficiency of $\mathrm{a}_{2}$-AP is extremely uncommon.

Case presentation: We report here a case of absolute deficiency of $\mathrm{a}_{2}$-AP in an 11-year-old Sudanese boy, who had a lifelong intermittent hemorrhagic tendency (gum bleeding, epistaxis, and exaggerated bleeding after trauma). Coagulation tests including prothrombin time, partial thromboplastin time, thrombin time, bleeding time, platelet count, clot retraction test, antithrombin, and factor VIII levels were within normal limits. Hepatic function tests and complete blood count were also normal. The main interesting finding in this patient was that the whole blood clot lysis was extremely fast, completed within 5-8 hours. The second abnormal finding is that the euglobulin clot lysis time was short. Nevertheless, the concentration of $\mathrm{a}_{2}$-AP in the patient's plasma was $0.2 \mathrm{lU} / \mathrm{ml}$ (reference range is 0.80-1.20 IU/ml). The addition of pooled plasma (with normal $\mathrm{a}_{2}$-AP) to the patient's whole blood corrected the accelerated fibrinolysis.
\end{abstract}

Conclusion: The study showed that $\mathrm{a}_{2}$-AP deficiency resulted in uninhibited fibrinolysis that caused the hemorrhagic tendency in this patient. Thus, this report demonstrates the significant role of $\mathrm{a}_{2}$-AP in coagulation.

Keywords: Alpha 2-antiplasmin ( $\mathrm{a}_{2}$-AP), Fibrinolysis, Bleeding tendency, Sudan

\section{Background}

The alpha 2plasmin inhibitor (previously known as $\alpha_{2}-$ antiplasmin $\left.\left[\alpha_{2}-\mathrm{AP}\right]\right)$ is a glycoprotein with an estimated molecular mass of approximately $51 \mathrm{kDa}$ that works as an essential, rapid-acting physiological inhibitor of free plasmin, and therefore has a basic role in the regulation of fibrinolysis [1]. $\alpha_{2}$-AP is synthesized in the liver. At the same time, it is found in the $\alpha$-granules of platelets, and secreted when platelets are activated. More recently, $\alpha_{2}-$ AP has been discovered in the kidney and brain [2]. $\alpha_{2-}$ AP is also a member of the serpin family of proteins. The gene coding for $\alpha_{2}$-AP is located on chromosome 17 . The mean value of $\alpha_{2}$-AP in the plasma of healthy subjects is

${ }^{*}$ Correspondence: bashirbashir17@hotmail.com Hematology Department, Faculty of Medical Laboratory Sciences, Port Sudan Ahlia College, Port Sudan, Sudan
$0.8-1.2 \mathrm{IU} / \mathrm{ml}$, and it inhibits the plasmin generated when all the plasminogen in the plasma is entirely activated to plasmin [3]. The concentration is likewise decreased in liver disease or as a result of its utilization in a fibrinolytic state such as disseminated intravascular coagulation (DIC), amyloidosis, solid tumor, acute promyelocytic leukemia (APL), or thrombolytic treatment [4]. Two types of $\alpha_{2}$-AP are available in the blood: $70 \%$ of $\alpha_{2}$-AP binds plasminogen and has inhibitory activity, while the remaining $30 \%$ is in a nonbinding form. The nonbinding form is the result of degradation of the binding form and has minimal inhibitory action [5]. Fibrinolysis is managed by $\alpha_{2}$ AP in three different ways: first, by the development of a stoichiometric complex with plasmin, where $\alpha_{2}$-AP is significantly more effective in inhibiting free plasmin than plasmin bound to the fibrin clot, and this permits limited plasmin production on the fibrin clot (Fig. 1); second, by original author(s) and the source, provide a link to the Creative Commons licence, and indicate if changes were made. The images or other third party material in this article are included in the article's Creative Commons licence, unless indicated otherwise in a credit line to the material. If material is not included in the article's Creative Commons licence and your intended use is not permitted by statutory regulation or exceeds the permitted use, you will need to obtain permission directly from the copyright holder. To view a copy of this licence, visit http://creativecommons.org/licenses/by/4.0/. The Creative Commons Public Domain Dedication waiver (http://creativeco mmons.org/publicdomain/zero/1.0/) applies to the data made available in this article, unless otherwise stated in a credit line to the data. 


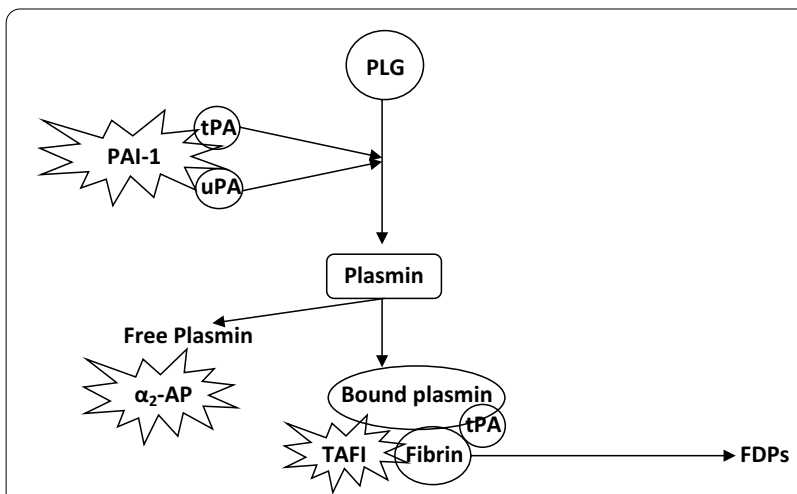

Fig. 1 Fibrinolysis: role of alpha 2-antiplasmin. PLG plasminogen, tPA tissue plasminogen activator, UPA urokinase type plasminogen activator, PAl-1 plasminogen activator inhibitor-1, $a_{2}-A P$ alpha 2-antiplasmin, TAFI thrombin-activatable fibrinolysis inhibitor

the inhibition of plasmin adsorption on the fibrin thrombus, where $\alpha_{2}$-AP is covalently bound into the fibrin clot by factor XIIIa, inhibiting fibrinolysis by fibrin coagulation; and third, by preventing the engagement of plasminogen in the fibrin clot. $\alpha_{2}$-AP responds quickly with plasmin to form a steady plasmin-antiplasmin complex. This communication is key to the physiological control of fibrinolysis and irreversibly blocks plasmin action, which in turn partially debases $\alpha_{2}$-AP. The plasminantiplasmin complex is cleared more quickly from the circulation [6]. When the amount of plasmin generated exceeds the capacity of $\alpha_{2}$-AP to neutralize plasmin, the $\alpha_{2}$-macroglobulin can act as a less functional reinforcement inhibitor. In this respect, $\alpha_{2}$-AP represents roughly 90\% of free plasmin inhibition in vivo [4].

In this report, we describe a patient with an inherited deficiency of $\alpha_{2}$-AP. This patient had shown a bleeding tendency since early life. $\alpha_{2}$-AP deficiency, which induced increased fibrinolytic activity, was the only abnormality present. To the best of the author's knowledge, this is the first case of $\alpha_{2}$-AP deficiency to be reported in Sudan.

\section{Case presentation}

An 11-year-old Sudanese boy presented with frequent bleeding diathesis (ecchymosis, epistaxis, and gingival bleeds) (Fig. 2). The most commonly encountered type of hemorrhage was extensive bleeding after trauma followed by subcutaneous bleeding. The patient had a history of delayed bleeding episodes since the day of circumcision, which took approximately 1 month to stop. Repeated episodes of epistaxis were also reported. He did not receive blood or blood product transfusion. He reported bleeding in the subcutaneous tissue following trauma when he was playing with his friends. Hemorrhage into joints also occurred after trauma. Spontaneous joint bleeding was

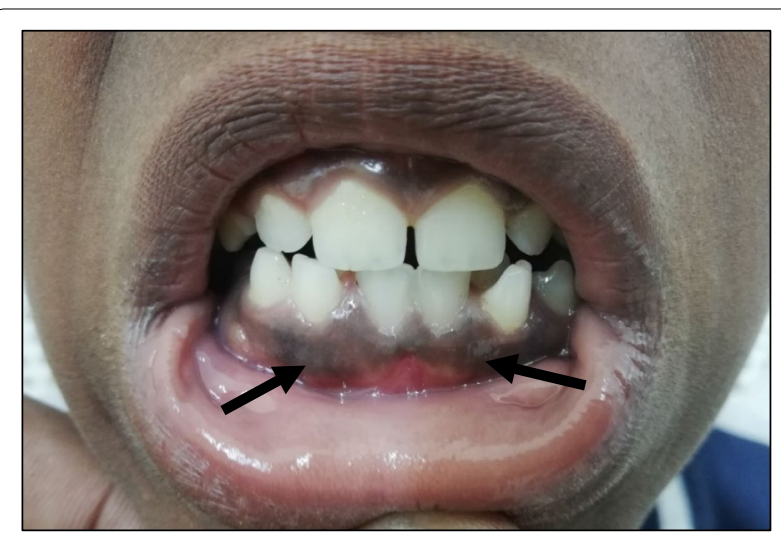

Fig. 2 Gingival bleeding in the patient (black arrows)

not reported. Pain and slight swelling of muscles sometimes persisted for months. Looking into the family history, all family members were normal except his mother. The mother had a history of severe interval bleeding diathesis (menorrhagia). The patient had no known chronic sickness, drug allergies, or any developmental abnormality.

On examination, the patient was neither icteric nor cyanosed, and was not dysmorphic. There was no noticeable change when checking the ear, nose, and throat. The cardiopulmonary examination was normal. The patient's central nervous system examination showed good sensation and reflexes. He had no skin rash or organomegaly. The liver function tests and complete blood count were all normal. Viral screening for human immunodeficiency virus (HIV), hepatitis $B$ virus (HBV), and hepatitis $C$ virus $(\mathrm{HCV})$ were negative (Table 1$)$.

The coagulation tests were performed when he was asymptomatic. The main abnormal investigations were as follows: fast lysis of whole blood clots and shortened euglobulin lysis time. The other tests including clotting time, prothrombin time (PT), partial thromboplastin time (PTT), and thrombin time (TT) were all within the normal values. This suggests that there were no abnormal changes in blood coagulation. This was further confirmed by the testing of coagulation factor activity. Platelet count, bleeding time, and von Willebrand factor were also normal (Table 2).

Concerning the clot lysis test, the blood was collected and promptly placed in a glass test tube and incubated at $37^{\circ} \mathrm{C}$. The clot was formed and retracted normally, but then underwent lysis. Following a few hours of incubation (5-8 hours with interval assessment), the clot was hardly visible, and it was just a small strand of fibrin. The fibrinogen and D-dimer concentration were within normal limits. To determine the status of fibrinolysis, euglobulin lysis time was calculated, and the result 
Table 1 Routine investigation of the patient

\begin{tabular}{|c|c|c|}
\hline Variables & Patient results & $\begin{array}{l}\text { Normal or } \\
\text { control }\end{array}$ \\
\hline White blood cells $\left(\times 10^{9} / \mathrm{l}\right)$ & 7.1 & $4-10$ \\
\hline Red blood cells $\left(\times 10^{12} / \mathrm{l}\right)$ & 4.56 & $3.5-5.5$ \\
\hline Hemoglobin $(\mathrm{g} / \mathrm{dl})$ & 12.5 & $12-16$ \\
\hline Hematocrit (\%) & 37.3 & $35-47$ \\
\hline Mean corpuscular volume (fl) & 81.8 & $78-98$ \\
\hline Mean corpuscular hemoglobin (pg) & 27.4 & $26-35$ \\
\hline Mean corpuscular hemoglobin concentration (\%) & 33.8 & $30-36$ \\
\hline Red cell distribution width-CV (\%) & 11.7 & $11.5-14.5$ \\
\hline Absolute lymphocyte count $\left(\times 10^{9} / \mathrm{l}\right)$ & 5.8 & $6-8.3$ \\
\hline Absolute neutrophil count $\left(\times 10^{9} / 1\right)$ & 1.3 & $1.5-6.0$ \\
\hline Platelet count $\left(\times 10^{9} / \mathrm{l}\right)$ & 345 & $150-400$ \\
\hline Mean platelet volume (fl) & 7.9 & $7.5-10.4$ \\
\hline Platelet distribution width (fl) & 9.3 & $9-17$ \\
\hline Platelet-large cell ratio (\%) & 12.7 & $13-43$ \\
\hline Reticulocyte count (\%) & 0.6 & $0.5-3 \%$ \\
\hline Bilirubin total (mg/dl) & 0.76 & $<1.1$ \\
\hline Bilirubin direct (mg/dl) & 0.09 & $<0.3$ \\
\hline Total protein (g/dl) & 7.4 & $6.6-8.3$ \\
\hline Albumin $(\mathrm{g} / \mathrm{dl})$ & 4.2 & $3.5-5.0$ \\
\hline Alanine transaminase (ALT) (U/I) & 22 & Up to 41 \\
\hline Aspartate transaminase (AST) (U/I) & 18 & Up to 40 \\
\hline Alkaline phosphatase (ALP) (U/I) & 120 & $<300$ \\
\hline Hepatitis C virus screening (HCV) & Negative & - \\
\hline Hepatitis B virus screening (HBV) & Negative & - \\
\hline Human immunodeficiency virus (HIV) screening & Negative & - \\
\hline
\end{tabular}

$C V$ coefficient of variation

Table 2 Hemostatic outcomes for the patient

\begin{tabular}{lll}
\hline Variables & $\begin{array}{l}\text { Patient } \\
\text { results }\end{array}$ & Normal or control \\
\hline Bleeding time (minutes) & 3.49 & $2-7$ \\
Clotting time (minutes) & 7.39 & $5-15$ \\
Clot retraction (\%) & 60 & $30-120$ \\
Platelet count ( $\mu l)$ & $345 \times 10^{9}$ & $150-450 \times 10^{9}$ \\
Prothrombin time (seconds) & 14.7 & $12-16$ \\
Partial thromboplastin time & 31.6 & $26-43$ \\
$\quad$ (seconds) & 16.4 & $8-18$ \\
Thrombin time (seconds) & 88 & $78-126$ \\
Antithrombin (\%) & $<0.1$ & Up to 0.3 \\
D-Dimer (mg) & 1.1 & $0.15-2.4$ \\
Von Willebrand factor : Ag (U) & 343 & $200-400$ \\
F I (mg) & 61 & $50-186$ \\
FVIII (\%) & 79 & $50-150$ \\
FX, & 91 & $60-130$ \\
F XIII (\%) & 54 & $90-240$ \\
Euglobulin lysis time (minutes) & $5-8$ & Negative at 24 hours \\
Whole clot lysis time (hours) & $5.8-1.2$ \\
a $_{2}$-antiplasmin (IU) & 0.2 & 0.8 \\
\hline
\end{tabular}

indicated shortened lysis time (Table 2). To further investigate, we treated the patient's plasma with a pooled normal plasma and repeated the euglobulin lysis time, which returned to normal. However, in such cases, it is preferable to use thromboelastometry to verify the diagnosis. Unfortunately, due to a lack of facilities, this technique was not performed. The defect seems to be inherited as an autosomal recessive trait (Fig. 3).

\section{Discussion and conclusion}

Human plasma contains numerous inhibitors of fibrinolysis. It may maintain a condition of harmony with activating segments of fibrinolysis [5]. An increased propensity for developing thromboembolism has been attributed to decreased levels of natural regulatory anticoagulant proteins [7]. The case depicted in this report indicates that a serious deficiency of $\alpha_{2}$-AP in plasma is associated with hyperfibrinolysis activity and a bleeding tendency. Therefore, this case demonstrates the significant role of $\alpha_{2}$-AP in the coagulation and fibrinolytic system. 


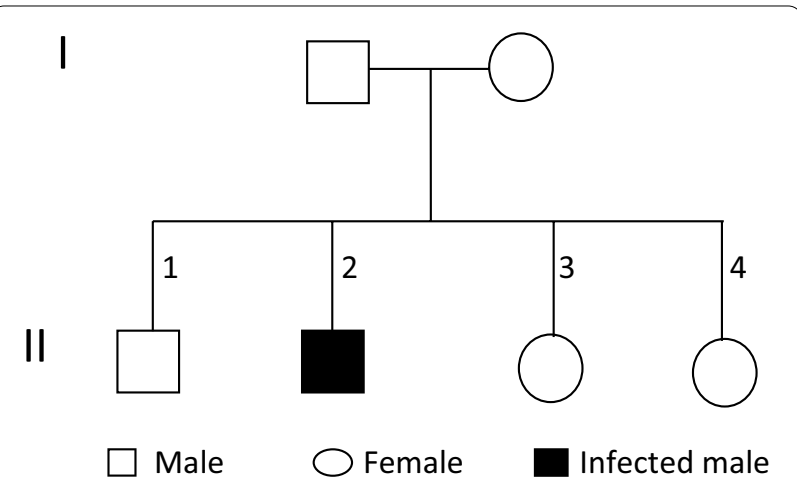

Fig. 3 Autosomal recessive trait pedigree of the Sudanese male patient with $a_{2}$-AP deficiency. Each subject can be located in the pedigree by a Roman numeral indicating generation. The patient (II 2) possessing $0.2 \mathrm{IU} / \mathrm{ml} \mathrm{a}_{2}$-AP in plasma was believed to be a heterozygote

In the absence of $\alpha_{2}$-AP, plasmin dissociates the essential hemostatic platelet-fibrin plug. In this way, it interferes with adequate primary hemostasis. Even if the formation of fibrin is healthy, the subsequent accelerated lysis of the formed fibrin plug (fibrinolysis) induces the onset of delayed bleeding. In this report, the patient has exhibited extensive bleeding after circumcision and minor injuries throughout his life. The patient did not develop hemarthrosis, and the symptoms and signs differed from those of hemophilia. In contrast to hemophilia, the patient's bleeding occurred mostly after trauma, while spontaneous bleeding was extremely uncommon. Unfortunately, due to a lack of awareness and ignorance on the part of the parents, the patient did not receive care until he reached teenage years and faced repeated bleeding episodes.

The striking change presented in this patient was that the spontaneous lysis of the blood clot was formed in vitro. Even though $\alpha_{2}$-AP is known to inhibit some activated clotting factors (XIa or thrombin) in coagulation systems [8], there were no atypical changes in the blood clotting tests of this patient. The unusual hyperfibrinolysis activity was attributed exclusively to a decrease in the level of $\alpha_{2}$-AP. The patient's blood was corrected to its normal level after adding pooled (normal) plasma containing a normal $\alpha_{2}$-AP level. This correction test for fibrinolysis was performed without any change that could influence the action of the inhibitors in the patient's sample.

When the blood clot forms, fibrinolysis will be activated. Eventually, the plasminogen turned to plasmin and bound to fibrin molecules [9]. Fibrinolysis depends solely on the plasmin that binds to fibrin. $\alpha_{2}$-AP diminishes the rate of binding of plasmin to fibrin, and consequently suppresses fibrin clot lysis. When blood lacks $\alpha 2-\mathrm{AP}$, as noted in this report, plasma activation of fibrinolysis will occur freely without any blockers. Therefore, $\alpha 2$-macroglobulin does not inhibit free plasma [10]. The formation of the hemostatic plug may be promptly lysed due to the lack of $\alpha_{2}$-AP. Fibrin strands are the major constituents of the clotting plug, and lysis of these strands may make the hemostatic plug extremely brittle. Since the laboratory results of blood clotting tests and platelet count in this patient were all within normal limits, the patient's bleeding diathesis was absolutely related to the inadequacy of $\alpha_{2}$-AP. Furthermore, the resulting disintegration of the hemostatic plug once formed (when the vessels are injured) is also due to $\alpha_{2}$-AP deficiency.

As the bleeding time, platelet count, clot retraction, and von Willebrand factor Ag levels were normal, these findings indicate that platelet functions were also normal. Despite the hyperfibrinolysis activity in this patient, the fibrinogen concentration was within the normal range. This indicates that abnormal fibrinogenolysis does not occur in vivo, as in this patient. It is possible that $\alpha_{2}$-macroglobulin, which was present at normal concentrations in this patient, prevents fibrinogenolysis by hindering the binding of plasmin to fibrin. $\alpha_{2}$-macroglobulin may also enable the inactivation of a variety of proteases (plasmin, kallikrein, and thrombin) [8].

On the other hand, the time of the euglobulin lysis test was shortened considerably. It is commonly believed that euglobulin lysis time reflects the overall fibrinolytic activity of plasma [5]. The shortened time of the euglobulin test for this patient, which was confirmed when $\alpha_{2}$ AP was corrected after the addition of pooled normal plasma, was probably not a direct result of excessive plasminogen activator activity. In reality, this was due to the absence of $\alpha_{2}$-AP in the patient's blood sample. The direct analysis of the $\alpha_{2}$-AP activity upheld this conclusion. The cause of the $\alpha_{2}$-AP deficiency in this patient's plasma cannot be determined. It could be due to a lack of synthesis of this protein in the hepatocyte or due to the hypercatabolism of $\alpha_{2}$-AP. Therefore, the origin of the $\alpha_{2}$-AP was most probably congenital. The gold-standard method for measurement of hyperfibrinolysis is by thromboelastometry. This was not performed due to lack of resources.

The clinical severity of the disease is assessed by the magnitude and the site of bleeding. Minor bleeding can be treated by oral antifibrinolytic agents, but more progressive bleeding may demand temporary plasma supplementation. Bleeding at critical locations may likewise require surgical intervention. Patients with congenital or acquired $\alpha_{2}$-AP deficiency who have extreme bleeding should receive fresh-frozen plasma (FFP) transfusion as a source of $\alpha_{2}$-AP. Antifibrinolytic agents such as 
aminocaproic acid or tranexamic acid, which prevent the production of plasmin and block its action, are used in response to active hemorrhage or as prophylaxis before any dental or surgical procedure [5]. The patient received doses of tranexamic acid and vitamin $\mathrm{K}$ that improved his condition.

Although the prevalence of $\alpha_{2}$-AP deficiency as a cause of hemorrhage is quite low as reported in the literature, this report confirms the presence of this disease in Sudan. Deficiency of $\alpha_{2}$-AP could contribute to a high level of free plasmin that can lead to a state of hyperfibrinolysis and bleeding.

\section{Abbreviations}

$\mathrm{a}_{2}$-AP: Alpha 2-antiplasmin; PT: Prothrombin time; PTT: Partial thromboplastin time; TT: Thrombin time; DIC: Disseminated intravascular coagulation; APL: Acute promyelocytic leukemia; HIV: Human immunodeficiency virus; HBV: Hepatitis B virus; HCV: Hepatitis C virus; AST: Aspartate aminotransferase; ALT: Alanine aminotransferase; ALP: Alkaline phosphatase.

\section{Acknowledgements}

Not applicable.

\section{Authors' contributions}

BA conceived and designed the study, wrote the manuscript, and read and approved the final manuscript.

\section{Funding}

No sources of funding for the research to report.

\section{Availability of data and materials}

The data sets used and/or analyzed during the current study are available from the corresponding author on reasonable request.

\section{Declarations}

\section{Ethics approval and consent to participate}

This study did not include experiments on animals or humans. The patient gave consent to use his details for this case study.

\section{Consent for publication}

Written informed consent was obtained from the parents of the patient (the patient's legal guardians) for publication of this case report and any accompanying images. A copy of the written consent is available for review by the Editor-in-Chief of this journal.

\section{Competing interests}

The author declares that they have no competing interests.

Received: 24 August 2020 Accepted: 22 March 2021

Published online: 07 May 2021

\section{References}

1. Carpenter SL, Mathew P. Alpha2-antiplasmin and its deficiency: fibrinolysis out of balance. Haemophilia. 2008;14:1250-4.

2. Reed GL, Houng AK, Singh S, Wang D. Alpha2-antiplasmin: new insights and opportunities for ischemic stroke. SeminThrombHemost. 2017:43(2):191-9.

3. Abdul S, Leebeek FW, Rijken DC, Willige SU. Natural heterogeneity of alpha2-antiplasmin: functional and clinical consequences. Blood. 2016;127(5):538-45.

4. Gebhart J, Kepa S, Hofer S, Koder S, Kaider A, Wolberg AS, Haslacher $\mathrm{H}$, Quehenberger P, Eigenbauer E, Panzer S, Mannhalter C, Pabinger I. Fibrinolysis in patients with a mild-to-moderate bleeding tendency of unknown cause. Ann Hematol. 2017;96:489-95.

5. Saes JL, Schols SEM, van Heerde WL, Nijziel MR. Hemorrhagic disorders of fibrinolysis: aclinical review. J Thromb Haemost. 2018;16:1498-509.

6. Rijken DC, Uitte de Willige S. Inhibition of fibrinolysis by coagulation factor XIII. Biomed Res Int. 2017;2017:1209676.

7. Igala M, Oukkach B, Khoubila N, Faez S, Benchekroun S. A congenital alpha2-antiplasmin deficiency. Ann Biol Clin. 2013;71:93-5.

8. Yasar Yildiz S, Kuru P, Toksoy Oner E, Agirbasli M. Functionalstability of plasminogen activator inhibitor-1. Sci World J. 2014;2014:858293.

9. Hirose J, Takedani H, Kubota M, Kinkawa J, Noguchi M. Total hip arthroplasty and total knee arthroplasty in a patientwith congenital deficiency of plasminogen activator inhibitor-1. Haemophilia. 2016:22:e237-9.

10. Iwaki T, Tanaka A, Miyawaki Y, Suzuki A, Kobayashi T, Takamatsu J, Matsushita T, Umemura K, Urano T, Kojima T, Terao T, Kanayama N. Lifethreatening hemorrhage and prolonged wound healing are remarkable phenotypes manifested bycomplete plasminogen activator inhibitor-1 deficiency inhumans. J ThrombHaemost. 2011;9:1200-6.

\section{Publisher's Note}

Springer Nature remains neutral with regard to jurisdictional claims in published maps and institutional affiliations.
Ready to submit your research? Choose BMC and benefit from:

- fast, convenient online submission

- thorough peer review by experienced researchers in your field

- rapid publication on acceptance

- support for research data, including large and complex data types

- gold Open Access which fosters wider collaboration and increased citations

- maximum visibility for your research: over 100M website views per year

At BMC, research is always in progress.

Learn more biomedcentral.com/submissions 